\title{
Investigation of Latent Heat Thermal Energy Storage System for Air- Conditioning Applications
}

\author{
Muath A. Alomai*, Yazeed A. Alomair, \\ School of Engineering, University of Guelph \\ Guelph, Ontario, Canada \\ *e-mail: alomairm@uoguelph.ca
}

\author{
Syeda Tasnim, Hussein A. Abdullah, Shohel Mahmud ${ }^{\psi}$, \\ School of Engineering, University of Guelph \\ Guelph, Ontario, Canada \\ * e-mail: smahmud@uoguelph.ca
}

\begin{abstract}
Around $40 \%$ of the total energy in USA is consumed by buildings, and about $\$ 370$ billion US dollar is spent each year to supply this energy and thus reduction in energy consumption is extremely important. One of the most effective and reliable ways to reduce energy consumption is the use of Phase Change Materials (PCMs) in Latent Heat Thermal Energy Storage (LHTES) systems. In this study an experimental setup was constructed to investigate the solidification process of PCM using two different types of heat exchangers: pipe heat exchanger and horizontal finned-pipe heat exchanger. The PCM used in this study is Rubitherm (RT-18) that has a melting point of $18^{\circ} \mathrm{C}$, and the heat transfer fluid (HTF) is water. To investigate the performance of pipe heat exchanger versus finned-pipe heat exchanger, two experiments were performed under identical initial, thermal and boundary conditions. The PCM is cooled down from $20^{\circ} \mathrm{C}$ to $5^{\circ} \mathrm{C}$ in both heat exchangers. Result of the temperature distribution as a function of time during the solidification process inside the TES system is presented and investigated. Visualization of the solidification process inside the TES system is also presented. Generally, the PCM is solid when its temperature is lower than the melting point, and it is liquid when its temperature is higher. PCM stores thermal energy during melting and releases heat as it solidifies. Both visualization and periodic temperature distribution results showed that as time progresses, the amount of the solid PCM increases in both heat exchangers. At a certain time, finnedpipe heat exchanger has higher amount of the solid PCM than the pipe heat exchanger. Also, the solidification time is reduced significantly when fins are added to the TES system. After 75,000 seconds of solidification, the average PCM temperature of pipe heat exchanger reached to $8.5^{\circ} \mathrm{C}$. Whereas, the average PCM temperature of the finned-pipe heat exchanger reached to $8.5^{\circ} \mathrm{C}$ after 19,000 seconds of solidification. Significant time reduction equivalent to 54,000 seconds is observed when the fins are added to the TES system. Employment of fin is preferred to improve heat transfer rate as the solidification process is enhanced due to the incorporation of fin.
\end{abstract}

Keywords- finned-pipe heat exchanger; pipe heat exchanger; phase change material; solidification; experimental investigation; solidificationv visualization; periodic temperature distribution

\section{INTROUCTION}

Buildings use approximately $40 \%$ of the total energy consumed in USA followed by industry and transportation [1]. Approximately $\$ 370$ billion US dollar is spent each year to supply this energy and thus reduction in energy consumption is extremely important [2]. One of the most efficient and reliable ways to reduce energy consumption is the use of PCMs in LHTES system [3]. Solid-liquid PCM have long been adopted as a thermal energy storage medium in LHTES system. Typically, a LHTES system consists of: (a) a PCM, (b) a container and (c) a thermal conductive surface for exchanging heat with the PCM $[4,5]$, a heat exchanger. In a typical LHTES system, a large amount of thermal energy is absorbed or released by the PCM during its nearly constant temperature phase change processes.

PCMs can be classified into (i) non-organic compounds (e.g., salt hydrate, metals, alloys) and (ii) organic compounds (e.g., wax). Organic PCMs can be further divided into (i) paraffinic PCMs (e.g., wax) and (ii) non-paraffinic PCMs (e.g., fatty acid). Paraffinic PCMs have extensively been used in LHTES system design because of their high latent heat of fusion, wide range of phase change temperatures, and good chemical stability [6]. Another advantage of paraffinic PCMs is that they have unlimited numbers of cycles [7]. However, PCMs have low thermal conductivity which results in reduction of the rate of melting and solidification of the PCMs [3]. Therefore, there are several ways to increase the performance of PCMs, such as using fins [8].

Bechiri and Mansouri [9] analyzed charging and discharging paraffin PCM in a shell and tube heat exchanger analytically. Anisur et al. [10] performed a 2-D analysis on a double wall circular tube heat exchanger with paraffin PCM for air cooling application. Heat Transfer Fluid (HTF) flow, pipes sizes and different radius of the PCM container were investigated analytically. Air was used as HTF, and the 
highest co-efficient of performance (COP) of the system was calculated to be 8.79 .

Anisur et al. [11] analytically and experimentally studied melting of PCM in a shell and tube heat exchanger for air cooling applications. They used Heptadecane PCM which had a melting point temperature of $22.33^{\circ} \mathrm{C}$. The analytical result was validated with the experimental result, and the $\mathrm{COP}$ of the system was calculated to be 4.16. Nithyanandam and Pitchumani [12] performed a numerical analysis on charging and discharging of PCM in finned heat pipes for concentrated solar power applications. The authors observed an enhancement of heat transfer by adding vertical fins, the larger the number of fins, the higher the heat transfer. Liu et al. [13] investigated melting characteristics of Paraffin PCM surrounding heat pipes. They found that when the inlet temperature of the heat pipe is increased, the total heat storage capacity and heat storage rates are increased. Also, the total heat storage capacity and heat storage rates are increased with decreasing the initial temperature of heat storage material. Khalifa et al. [14] performed an experimental and numerical study on PCM solidification around tube integrated with vertical fins versus a bare tube for solar thermal power generation application. Their findings illustrated that heat transfer performance was improved $24 \%$ compared to a bare tube.

Khalifa et al. [15] performed an experimental investigation on solidification of a high temperature PCM in a finned heat pipe duct. A significant improvement in the heat transfer rate was observed for the finned heat pipe case especially during later times of the solidification process. Li et al. [16] experimentally studied the melting and solidification of PCM in a flat heat exchanger with heat pipes. The system's performance showed a uniform temperature across the heat exchanger and an increase in the heat transfer inside the PCM. Rahimi et al. [8] performed an experimental analysis on melting and solidification of PCM inside a thermal energy storage system using copper pipes and aluminum fins. They found that when the aluminum fins were added to their system, the heat transfer in the PCM was increased. Other studies [17, 18] experimentally investigated melting performance of PCMs by using heat pipes. They studied the performance of their systems with increasing the heat pipe numbers and increasing the power input of the heat pipes. An enhancement of heat transfer was observed with increase in the numbers of heat pipes and input power of heat pipes.

Based on the literature review above, there is a lack of experimental studies that examined the effect of solidification (heat discharging) of PCMs with copper fins. The aim of this study is to compare the performance of a tube heat exchanger and finned-tube heat exchanger experimentally. RT-18 Rubitherm is used as PCM, and water is used as a heat transfer fluid (HTF). To compare the performance, transient temperatures are measured at different locations and visualization of the solidification process is performed. This information will enable us to assess the performance of heat exchanger with fins and help to able to understand the fundamental of liquid-solid phase transition and heat transfer during solidification of PCM.

\section{EXPERIMENTAL SETUP AND PROCEDURES}

\section{A. Description of experimental set-up}

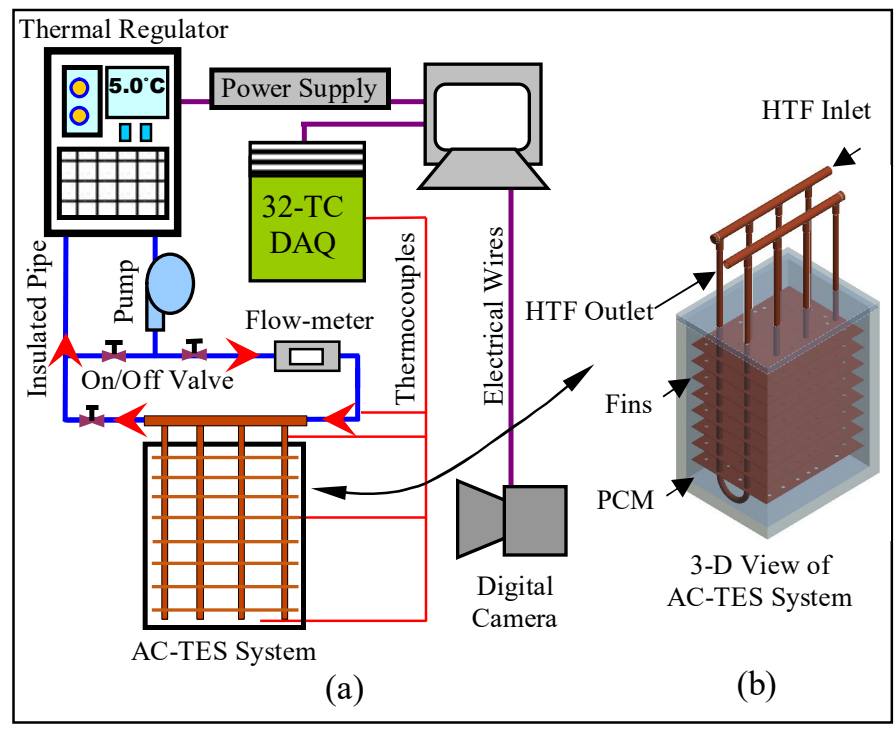

Figure 1: Schematic diagram of the (a) experimental setup and (b) components of thermal energy storage system (TES).

An experimental set-up was designed and built in order to visualize and investigate the solidification process of the PCM in LHTES system. Figure 1(a) shows a schematic diagram of the experimental set-up, and figure 1(b) shows the finned TES system. The experimental set-up in figure 1(a) consists of a (Polystat recirculator, model: 13042-01, supplier: Cole-Parmer) that controls water inlet temperature; a water pump (model: FP1, supplier: Cole Parmer), and a series of valves to regulate water flow rate; a digital flow meter (model: RT-375MI-LPM2, supplier: Blue-White) and the heat storage system. The set-up allows replacing readily the heat exchanger with no changes in the rest of equipment. $32 \mathrm{~K}$-type thermocouples (model: 5TCTT-K-30-36, supplier: Omega) were installed at different locations inside the TES system and the copper pipes to record temperatures at different times. These measurements were performed to ensure that the PCM was well distributed within all pipes and sheets. Temperatures were recorded as function of time in a computer via the DAQ system (model: NI9213, supplier: National Instruments) using LabView software (version: 15, supplier: National Instruments). A digital camera (model: EOS rebel T5, supplier: Canon) is connected to the computer to capture the images during the experiment periodically. The external surface of the TES system was totally covered with insulation foam to minimize heat losses. For both pipes and finned-pipes heat exchangers, the following temperatures measurements were taken: ambient temperature; water inlet and outlet temperatures of the TES system; water inlet and outlet temperatures for each U-shaped copper pipe; and halfway between water inlet and outlet of each U-shaped copper pipe (at the bottom point). The rest of the 17 thermocouples were distributed evenly through the PCM for 
the pipes heat exchanger. To measure the temperature distribution across the copper sheet wall for the finned-pipes heat exchanger, 5 thermocouples were distributed in the middle copper sheet (4 corners and 1 in the center). To measure the temperature distribution across the PCM, 12 thermocouples were evenly distributed in three elevations ( 4 corners for each elevation). The TES system in figure 1(b) consists of a transparent acrylic container filled with a PCM, copper pipes and copper sheets. The outer surface of the TES system was made of a $30-\mathrm{cm}$ height, $24.5-\mathrm{cm}$ width and $20-\mathrm{cm}$ depth. The thickness of the transparent acrylic wall is 1-cm (supplier: McMaster Carr). The used PCM is Rubitherm (RT-18) (supplier: Rubitherm) that has a solidifying range of $19^{\circ} \mathrm{C}-$ $17^{\circ} \mathrm{C}$, heat storage capacity of $250 \mathrm{~kJ} / \mathrm{kg}$, and a max operation temperature of $48^{\circ} \mathrm{C}$. The volume of PCM was $0.01 \mathrm{~m} 3$. Four U-shaped vertical copper pipes of a diameter of $0.9525 \mathrm{~cm}$

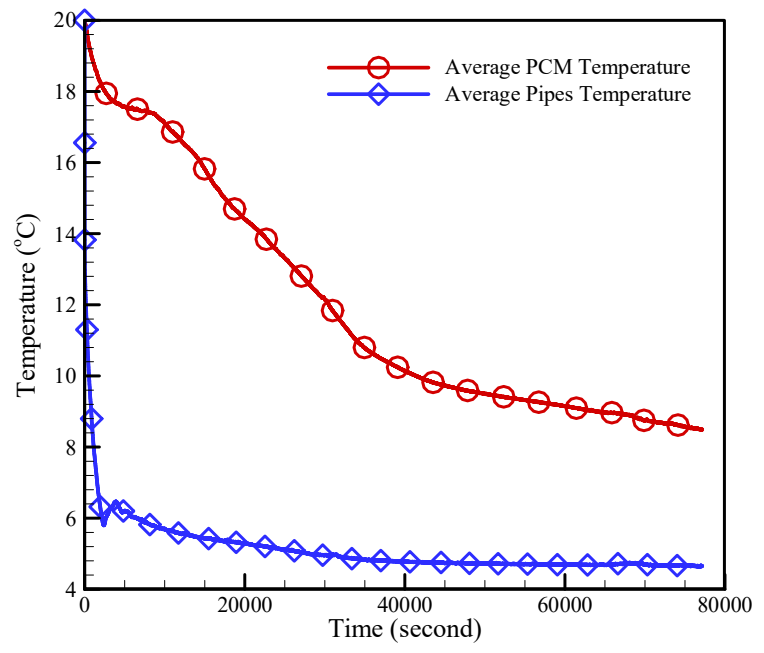

(a)

\section{RESULTS AND DISCUSSION}

\section{A. Temperature distribution of the solidification process}

Figures 2 (a) and (b) present periodic average temperature variation of the pipes, PCM and fins at different locations inside the TES system. The red curve represents the average PCM temperature while the average pipes temperature is presented in the blue curve. For the finned-pipes heat exchanger, the green curve represents the fins temperature. In general, the PCM is liquid when its temperature is higher than the melting point temperature $\left(18^{\circ} \mathrm{C}\right)$, and it solidifies when its temperature is lower. Initially, the PCM is liquid, and the temperature of the $\mathrm{PCM}$ is $20^{\circ} \mathrm{C}$. The solidification process is initiated when cold water at $5^{\circ} \mathrm{C}$ is bypassed through the copper pipes. The liquid PCM around the tube absorbs thermal

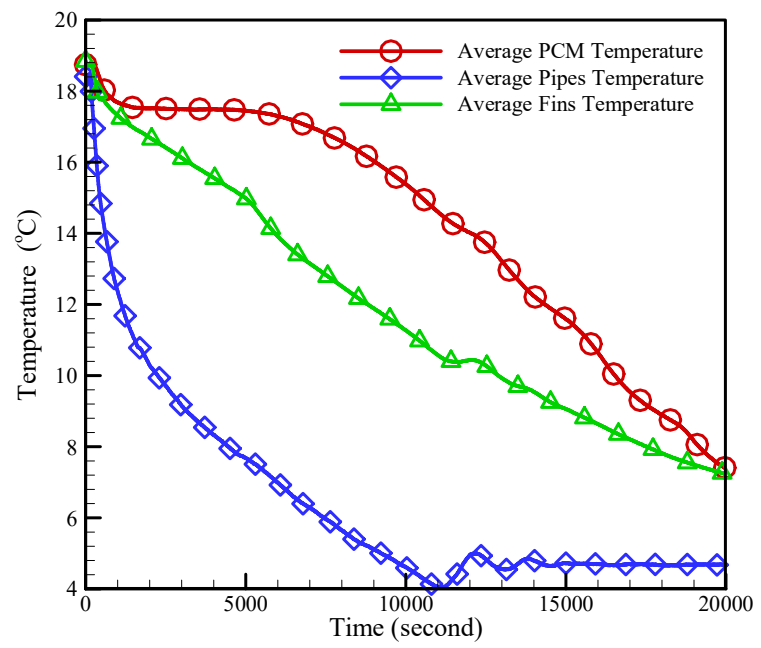

(b)

Figure 2: (a) Temperature distribution $\left({ }^{\circ} \mathrm{C}\right)$ versus time (second) for solidification process inside the pipe heat exchanger and (b) Temperature distribution $\left({ }^{\circ} \mathrm{C}\right.$ ) versus time (second) for solidification process inside the finned-pipe heat exchanger.

(0.375 inch) were passed through the center of the PCM. Pipes were distributed evenly from each side: 6-cm away from the front and back walls and 1-cm away from right and left side walls. These copper pipes carried water as the heat transfer fluid during the experiment. Eight horizontal copper sheets of $21.5-\mathrm{cm}$ width, $16.5-\mathrm{cm}$ depth, and 1-mm thickness are aligned on the base with $3-\mathrm{cm}$ spacing between them. The fins were soldered to the pipes to minimize the thermal contact resistance between the heat exchanger parts.

\section{B. Experimental Procedure}

The experiments were conducted in several steps. First, the TES system was filled with RT-18 PCM. Second, the temperature of the $\mathrm{PCM}$ was heated up to about $20^{\circ} \mathrm{C}$ (liquid phase). Third, the water of thermal regulator was cooled down to $5^{\circ} \mathrm{C}$ and supplied to the TES system through the copper pipes. Meanwhile, the temperatures of the water flow, copper sheets and PCM were recorded at each 10 second. Also, images of the solidification process were captured at each 10minute interval. energy from the cold water (HTF) via the tube surface, removes the sensible heat of the PCM and drops the temperature down to the freezing point. The PCM starts solidifying around the tube in the radial direction when the temperature drops below freezing point temperature. The thickness of the solid PCM grows with time around the tube. This solid PCM around the tube then behaves as an insulation material due to its low thermal conductivity compared to the copper tube material and slowed down the solidification process. Heat transfer through the solid PCM is dominated by conduction and as the thickness of the solid PCM increases around the tube, the heat transfer from the tube surface is further reduced. This reduction in heat transfer enhances the solidification time for a bare tube case. Adding horizontal copper fins decreases the thermal resistance during the solidification process and enhances the solidification time. The verage PCM temperature of pipe heat exchanger results shown in figure 2 (a) reached to $8.5^{\circ} \mathrm{C}$ after 75,000 seconds of cooling. The results of the finned-pipe heat exchanger in figure 2 (b) showed that the average PCM temperature reached 


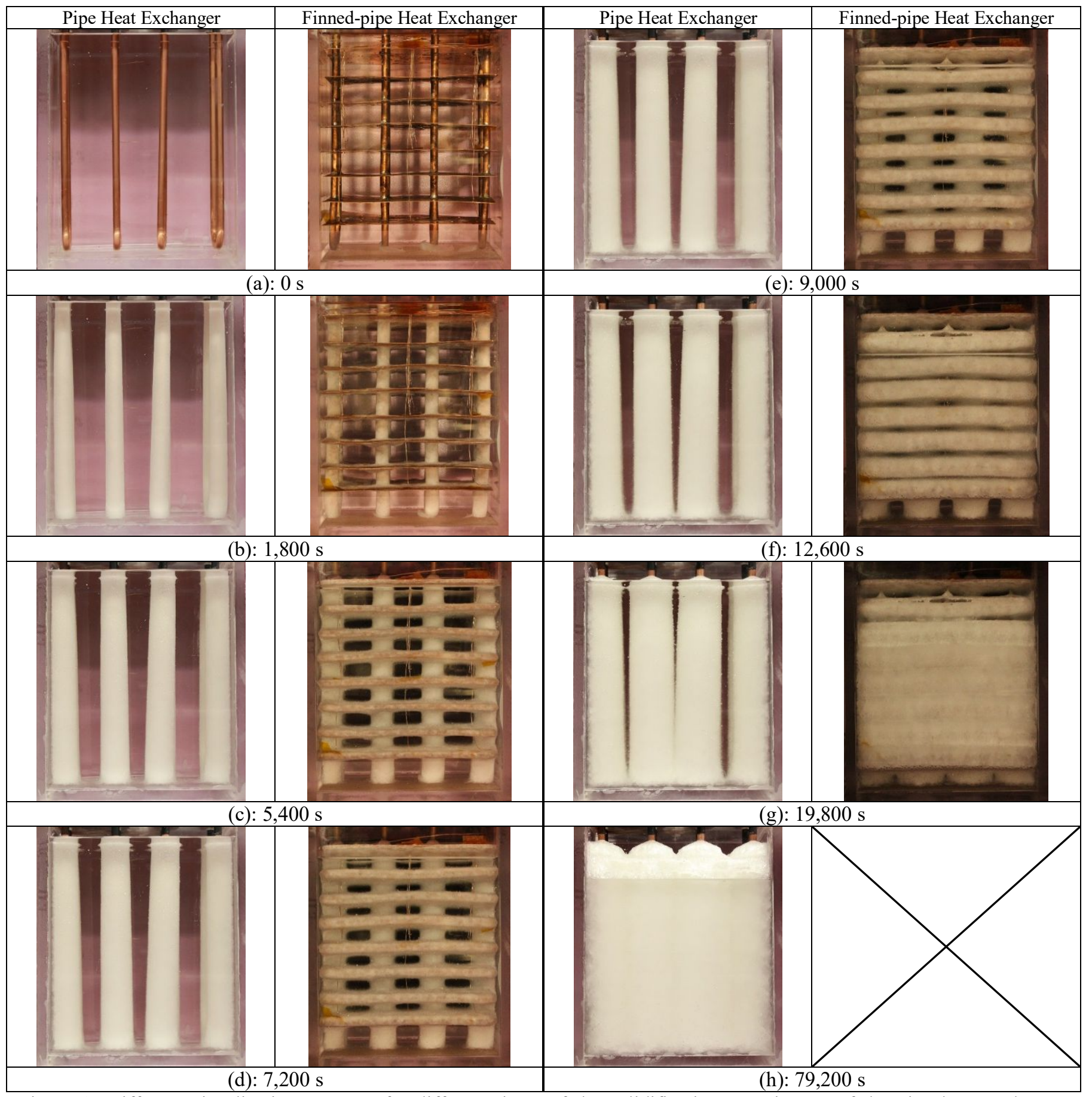

Figure 3: Different visualization captures for different times of the solidification experiments of the pipe heat exchanger versus finned-pipe heat exchanger. For the finned-pipe heat exchanger, the solidification process ends at 19,800 $\mathrm{s}$ and that is why no figure is provided to the last row $(\mathrm{h})$ in the right column.

to $8.5^{\circ} \mathrm{C}$ after 19,000 seconds of cooling. When the fins were added to the TES system, 54,000 seconds was reduced.

\section{B. Visualization of the solidification process}

Figure 3 shows visualization pictures captured of the solidification experiments of the pipe heat exchanger versus finned-pipe heat exchanger for different times from 0 second to 79,200 seconds (a-h). The left column represents the pipe heat exchanger experiment, and right column represents finned-pipe heat exchanger experiment. Each row represents a visualization comparison between pipe heat exchanger versus finned-pipe heat exchanger for the same boundary and thermal 
conditions at a certain time. In general, the PCM is liquid when its temperature is higher than the melting point temperature $\left(18^{\circ} \mathrm{C}\right)$, and it solidifies when its temperature is lower. At 0 second, the PCM is liquid, and the temperature of the PCM is $20^{\circ} \mathrm{C}$. The solidification process is initiated when cold water at $5^{\circ} \mathrm{C}$ is bypassed through the copper pipes any time after 0 second. It is observed that the amount of the solid PCM increases with time progression for both heat exchangers. Also, it is noticed that the amount of the solid PCM in finned-pipe heat exchanger is higher than the pipe heat exchanger.

\section{CONCLUSION}

An experimental set-up was constructed to investigate the solidification process of two heat exchangers (pipe heat exchanger versus finned-pipe heat exchanger). The PCM used in this study was RT-18 that has a melting point temperature of $18^{\circ} \mathrm{C}$. Water was used as heat transfer fluid. Two experiments were performed under identical initial, thermal and boundary conditions to investigate the performance of pipe heat exchanger versus finned-pipe heat exchanger. Periodic temperature distribution and visualization results of the solidification process inside the TES system were presented. Generally, the PCM is liquid when its temperature is higher than the melting point temperature $\left(18^{\circ} \mathrm{C}\right)$, and it solidifies when its temperature is lower. Also, PCM releases heat as it solidifies. Results for both heat exchangers showed that the amount of the solid PCM increases with time progression. Temperature distribution results indicated that the amount of the solid PCM in finned-pipe heat exchanger is higher than the pipe heat exchanger at a fixed time. To reach $8.5^{\circ} \mathrm{C}$ in the solidification process, the average PCM temperature of pipe heat exchanger needed 75,000 seconds and the average PCM temperature of finned-pipe heat exchanger needed 19,000 seconds. Therefore, 54,000 seconds is reduced once the fins were added to the TES system.

\section{REFERENCES}

[1] Collins, M. (2017). Solar Thermal Research Laboratory (STRL). https://uwaterloo.ca/solar-thermal-research-laboratory/about.

[2] US DOE Building Windows and Envelope R\&D -Retrofit Focus EcoBuild December 10th, 2014.

[3] A. Sharma, V.V. Tyagi, C.R. Chen, D. Buddhi, Review on thermal energy storage with phase change materials and applications. Renewable Sustainable Energy Reviews, 13, 3183-3145, 2009.

[4] Lacroix, M., "Study of the heat transfer behavior of a latent heat thermal energy storage unit with finned tube", Int. J. Heat Mass Transfer, 36, (8), 2083-2092, 1993.

[5] Lacroix, M. "Numerical simulation of a shell and tube latent heat thermal energy storage unit". Solar Energy, 50, (4), 357-367, 1993.

[6] X.X. Han, Y. Tian, C.Y. Zhao. An effectiveness study of enhanced heat transfer in phase change materials (PCMs). Int. J. Heat Mass Transfer, 60, 459-468, 2013.

[7] (2017). Rubitherm Advantages. https://www.rubitherm.eu/pcm.html.

[8] M. Rahimia, A.A. Ranjbar, D.D. Ganji, K. Sedighi, M.J. Hosseini, R. Bahrampoury, Analysis of geometrical and operational parameters of PCM in a fin and tube heat exchanger, International Communications in Heat and Mass Transfer, 53, 109-115, 2014.

[9] M. Bechiri, K. Mansouri, Analytical solution of heat transfer in a shell-and-tube latent thermal energy storage system, Renewable Energy, 74, 825-838, 2015.

[10] M.R. Anisur, M.A. Kibria, M.H. Mahfuz, R. Saidur, I.H.S.C. Metselaar, Analysis of a thermal energy storage system for air cooling-heating application through cylindrical tube, Energy Conversion and Management, 76, 732-737, 2013.

[11] M.R. Anisur, M.A. Kibria, M.H. Mahfuz, R Saidur, I.H.S.C. Metselaar, Cooling of air using heptadecane phase change material in shell and tube arrangement: Analytical and experimental study, Energy and Buildings, 85, 98-106, 2014.

[12] K. Nithyanandam, R. Pitchumani, Computational studies on a latent thermal energy storage system with integral heat pipes for concentrating solar power, Applied Energy, 103, 400-415, 2013.

[13] X. Liu, G. Fang, Z. Chen, Dynamic charging characteristics modeling of heat storage device with heat pipe, Applied Thermal Engineering, 31, 2902-2908, 2011.

[14] A. Khalifa, L. Tan, A. Date, A. Akbarzadeh, A numerical and experimental study of solidification around axially finned heat pipes for high temperature latent heat thermal energy storage units, Applied Thermal Engineering, 70, 609-619, 2014.

[15] A. Khalifa, L. Tan, A. Date, A. Akbarzadeh, Performance of suspended finned heat pipes in high-temperature latent heat thermal energy storage, Applied Thermal Engineering, 81, 242-252, 2015.

[16] F. Li, Y. Diao, Y. Zhao, T. Zhu, J. Liu, Experimental study on the thermal performance of a new type of thermal energy storage based on flat micro-heat pipe array, Energy Conversion and Management, $112,395-403,2016$.

[17] J. Zhao, Z. Rao, C. Liu, Y. Li, Experimental investigation on thermal performance of phase change material coupled with closed-loop oscillating heat pipe (PCM/CLOHP) used in thermal management, Applied Thermal Engineering, 93, 90-100, 2016.

[18] Q. Wang, Z. Rao, Y. Huo, S. Wang, Thermal performance of phase change material/oscillating heat pipe-based battery thermal management system, International Journal of Thermal Sciences, 102, $9-16,6$. 